\title{
Germinação de sementes de paineira-do-campo (Eriotheca gracilipes (K. Schum.) A. Robyns) em diferentes temperaturas
}

\author{
Eriotecha gracilipes (K. Shum .) A. Robyns seeds germination at \\ different temperatures
}

\section{Ademir Kleber Morbeck de OLIVEIRA ${ }^{1}$; Jonathan Wesley Ferreira RIBEIRO ${ }^{2}$; Kelly Cristina Lacerda PEREIRA ${ }^{2}$; Cassila Andréa Araújo SILVA ${ }^{2}$}

${ }^{1}$ Prof. Dr., Universidade Anhanguera-Uniderp, Rua Alexandre Herculano, 1400 - Jardim Veraneio, CEP 79037280, Campo Grande, Mato Grosso do Sul. E-mail: akmorbeckoliveira@gmail.com

${ }^{2}$ Discente, Universidade Anhanguera-Uniderp, Rua Alexandre Herculano, 1400 - Jardim Veraneio, CEP 79037280, Campo Grande, Mato Grosso do Sul. E-mail: jwfribeiro@gmail.com, kellykams@hotmail.com, c_andreia29@hotmail.com

Recebido em: 30-07-2013; Aceito em: 16-06-2014

\section{Resumo}

A temperatura pode influenciar no processo de germinação, afetando principalmente a absorção de água e em todas as reações bioquímicas e processos fisiológicos relacionados à semente. Eriotheca gracilipes é uma espécie arbórea pertencente à família Malvaceae, distribuída pelos biomas Cerrado e Mata Atlântica. O objetivo deste trabalho foi determinar a temperatura adequada para a germinação e a produção de plântulas da espécie. Para sementes recém-colhidas, foram testadas temperaturas constantes de $20 ; 25 ; 30$ e $35^{\circ} \mathrm{C}$ e alternadas de $20-30$ e $25-35^{\circ} \mathrm{C}$, com quatro repetições de 25 sementes por tratamento e fotoperíodo de 24 h. Após 30 dias, sementes armazenadas em sacos de papel foram submetidas ao teste de germinação, nas temperaturas de 20 e $25^{\circ} \mathrm{C}$. $\mathrm{O}$ delineamento experimental foi o inteiramente casualizado, e as médias, comparadas pelo teste de Tukey, a $5 \%$. Ocorreu maior percentagem de germinação nas temperaturas de $20 ; 25$ e $20-30{ }^{\circ} \mathrm{C}$, atingindo $67 ; 70$ e $60 \%$, respectivamente, além de maiores índices de velocidade de germinação, respectivamente, 2,6; 2,8 e 2,3. O maior comprimento e a massa de matéria seca das raízes primárias foram obtidos igualmente nas temperaturas de $20 ; 25$ e $20-30^{\circ} \mathrm{C}$. Após 30 dias de armazenamento, a germinação atingiu $96 \%$ e índice de velocidade de germinação de 6,3.

Palavras-chave adicionais: espécies de cerrado; Malvaceae; sementes florestais.

\begin{abstract}
Temperature may affect the germination process mainly that of water absorption and all the biochemical reactions and physiological processes related to the seeds. Eriotecha gracilipes is a tree species of the Malvaceae family found in the Savannah and Atlantic Forest biomes. The objective of this work was to find the adequate temperature for the germination of the seeds and the production of seedlings of that species. Recently harvested seeds were submitted to the constant temperatures of $20,25,30$, and $35^{\circ} \mathrm{C}$ and the alternate temperatures of $20-30$ and $25-35^{\circ} \mathrm{C}$ with four repetitions of 25 seeds each and photoperiod of $24 \mathrm{~h}$. Having elapsed a period of 30 days, seeds stored in paper bags were submitted to the germination test at the temperatures of 20 and $25^{\circ} \mathrm{C}$. The highest germination percentages were verified at the temperatures of 20,25 , and $20-30{ }^{\circ} \mathrm{C}$ when values of, respectively, 67,70 , and $60 \%$ were attained. Speed of germination indexes were also the highest $(2.6,2,8$, and 2.3) under those temperatures. Primary roots length and dry weight were the highest under temperatures of 20,25 , and $20-30{ }^{\circ} \mathrm{C}$. After a storage period of 30 days, germination was of $96 \%$ and the speed of germination index of 6.3 .
\end{abstract}

Additional keywords: forest seeds; Malvaceae; Savannah species.

Introdução

A germinação é a retomada das atividades metabólicas do eixo embrionário, culminando na emissão da raiz primária, sendo uma fase crítica, pois, além de estar associada aos processos fisiológicos da semente, depende de fatores ambientais como água, luz e temperatura, entre outros (BRADFORD \& NONOGAKI, 2007; BRASIL, 2009; CARVALHO \& NAKAGAWA, 2012). No que se refere à temperatura, essa afeta significativamente o processo germinativo, influenciando principalmente na absorção de água pela semente e em todas as reações bioquímicas e processos fisiológicos relacionados à germinação. Porém, não há uma temperatura 
ótima e uniforme para a germinação de todas as espécies (BRADFORD \& NONOGAKI, 2007; CARVALHO \& NAKAGAWA, 2012).

A germinação ocorre dentro de determinados limites de temperatura, sendo a temperatura ideal aquela em que ocorre o máximo de germinação, no menor espaço de tempo (MARCOS FILHO, 2005; CARVALHO \& NAKAGAWA, 2012). Para espécies tropicais, a melhor faixa de temperatura encontra-se normalmente entre 20 e $35^{\circ} \mathrm{C}$ (LARCHER, 2003). Porém as espécies apresentam comportamento variável em relação à temperatura, embora $25^{\circ} \mathrm{C}$ seja considerada a temperatura mais adequada para a maioria das espécies do bioma Cerrado (BRANCALION et al., 2010). De acordo com CARVALHO \& NAKAGAWA (2012), as espécies florestais possuem sua temperatura ótima de germinação, variável em função da sua adaptação ao clima da região de origem.

A temperatura, além de afetar a germinação, também é fundamental para o desenvolvimento da plântula e da raiz primária, que geralmente é a primeira estrutura a emergir, tendo um papel crucial no processo de estabelecimento no ambiente. Temperaturas inadequadas afetando diretamente a raiz primária, que está em rápido processo de divisão celular, com qualquer fator ambiental adverso, podem levar a uma diminuição de sua capacidade de desenvolvimento (LARCHER, 2003).

Contudo, para a maioria das espécies nativas, não há ainda informações básicas sobre as melhores condições para a germinação, o que pode ser observado, por exemplo, em CARVALHO (2003, 2006, 2008, 2010), SALOMÃO et al. (1997, 2003) e BRASIL (2009), nos quais existem poucas informações para análise de sementes de espécies de Cerrado, levando-se em consideração a variada flora encontrada neste bioma.

Das espécies com poucas informações, pode-se citar a Eriotheca gracilipes (K. Schum.) A. Robyns, pertencente à família Malvaceae, com ocorrência no bioma Mata Atlântica, Cerrado e na transição para floresta latifoliada semidecídua, nos Estados de Mato Grosso do Sul, Goiás, Mato Grosso, Minas Gerais, São Paulo, Rio de Janeiro e Espírito Santo. Conhecida popularmente como paineira-do-campo, embiruçu e paina, entre outros nomes, atinge até 17 metros na floresta semidecídua e de 4 a 6 metros no Cerrado (LORENZI, 2008).

A paineira-do-campo é uma espécie arbórea semidecídua, heliófila e característica de formações secundárias, com madeira leve e pouco resistente, empregada na confecção de forros, caixotaria e pasta celulósica e recomendada para paisagismo e reflorestamentos (LORENZI, 2008), com seus frutos servindo de alimento para a fauna, principalmente psitacídeos
(FRANCISCO et al., 2008), além de possuir utilização na medicina popular (GUARIM NETO \& MORAIS, 2003).

Diante do exposto, o presente trabalho objetivou avaliar o efeito de temperaturas na germinação e na formação de plântulas de paineira-do-campo.

\section{Material e métodos}

Foram coletados frutos de Eriotheca gracilipes, em outubro de 2010, de 14 árvores adultas localizadas em áreas de matas naturais fragmentadas (Cerrado Denso, Típico e Ralo RIBEIRO \& WALTER, 1998), intercaladas com locais de pastagens e morros, na região do Taboco, município de Corguinho (Latitude $19^{\circ} 49^{\prime} 57^{\prime \prime}$ sul, Longitude 544ㅇ'45" oeste, $290 \mathrm{~m}$. alt.) - MS, Brasil. Os frutos coletados, entre $10 \mathrm{e}$ 20 por árvore, encontravam-se aparentemente maduros com aspecto seco e abertura parcial dos lóculos; após a coleta, os mesmos foram acondicionados em sacos de papel e transportados para o Laboratório de Pesquisa em Sistemas Ambientais e Biodiversidade, da Universidade Anhanguera-Uniderp, Campo Grande-MS, Brasil.

Em laboratório, os frutos foram deixados sobre uma bancada forrada com papel pardo, em temperatura ambiente, até a abertura, com extração posterior das sementes, separando-as das "plumas", manualmente, com a realização do teste de umidade, seguindo método de estufa a $105+3{ }^{\circ} \mathrm{C}$ por 24 horas, de acordo com BRASIL (2009).

As sementes utilizadas para o teste de germinação passaram por assepsia superficial, por imersão em hipoclorito de sódio a $2 \%$, por três minutos, sendo em seguida lavadas em água corrente, por um minuto. O teste de germinação foi conduzido nas temperaturas constantes de 20; $25 ; 30$ e $35^{\circ} \mathrm{C}$ e alternadas de $20-30$ e $25-35^{\circ} \mathrm{C}$, com quatro repetições de 25 sementes por tratamento e fotoperíodo de $12 \mathrm{~h}$ de luz branca (quatro lâmpadas fluorescentes de $20 \mathrm{~W}$ ), em câmaras de germinação. Os testes foram conduzidos em caixas de plástico transparente $(11 \times 11 \times 3,5 \mathrm{~cm})$, sobre duas folhas de papel germitest previamente umedecidas com uma solução aquosa do fungicida Rovral a $0,1 \%$ $(\mathrm{m} / \mathrm{v})$, aplicado em volume da solução equivalente a 2,5 vezes a massa do papel não hidratado (BRASIL, 2009).

Uma amostra das sementes foi acondicionada em saco de papel pardo e armazenada em armário de madeira em laboratório, com temperatura média de $28,5{ }^{\circ} \mathrm{C}$ e umidade relativa entre 60 e $70 \%$. Após 30 dias, o teste de germinação, nas temperaturas de 20 e $25^{\circ} \mathrm{C}$, foi repetido com as sementes armazenadas, seguindo os procedimentos citados anteriormente. 
A avaliação da germinação foi diária, sendo iniciada no primeiro dia após a instalação do teste e encerrada no $10^{\circ}$ dia, considerando-se germinadas as sementes com emissão de raiz primária, utilizando-se do critério fisiológico de germinação (LABOURIAU, 1983), com, no mínimo, $2 \mathrm{~mm}$ de comprimento. Ao final do teste, calculou-se a percentagem de germinação, de acordo com a fórmula de BORGHETTI \& FERREIRA (2004) [\%G $\left.=\left(\sum n_{i} N^{-1}\right) 100\right]$, e o vigor das sementes, medido indiretamente pelo tempo médio de germinação em dias (TMG), quantificando a germinação sob o ponto de vista cinético (LABOURIAU \& AGUDO, 1987) e pelo índice de velocidade de germinação (IVG) (MAGUIRE, 1962), além do comprimento e da massa seca de raízes primárias.

Para a avaliação do comprimento das raízes primárias, foram utilizadas todas as plântulas provenientes dos testes de germinação, ao término do experimento, medidas em milímetros, usando paquímetro digital.

Posteriormente, as raízes foram seccionadas com bisturi, acondicionadas em sacos de papel devidamente identificados e levadas para estufa de ventilação forçada à temperatura de $50^{\circ} \mathrm{C}$ por 24 horas e, então, pesadas individualmente em balança analítica, sendo expresso o resultado em gramas por plântula (massa seca).

As sementes não germinadas foram seccionadas com auxílio de bisturi e observadas através de estereomicroscópio, para avaliação de degradação de estruturas, de acordo com BRASIL (2009).

O delineamento experimental foi o inteiramente casualizado. Não foi necessária a transformação dos dados de germinação, IVG e TMG. Os dados das características avaliadas foram submetidos à análise de variância e, quando ocorreu significância, realizou-se a comparação das médias, utilizando-se do teste de Tukey, a $5 \%$ de probabilidade. As análises estatísticas foram processadas om o uso do programa estatístico Assistat 7.7 beta.

\section{Resultados e discussão}

As sementes recém-colhidas de Eriotheca gracilipes apresentaram $15,9 \%$ de teor de água. 0 valor encontrado é acima do citado para outra espécie do mesmo gênero, E. pubescens (Mart. \& Zucc.) Schott \& Endl., com $11,1 \%$ ou outras espécies da família Malvaceae, como Apeiba tibourbou Aubl., 10\%, Chorisia speciosa A.St.-Hil., $7,5 \%$ ou Guazuma ulmifolia Lam., 10\% (SALOMÃO et al., 1997; WETZEL, 1997 citado por SALOMÃO et al., 2003). De acordo com CARVALHO (2003), as sementes de algumas espécies da família Malvaceae (ex Bombacaceae), como C. speciosa, podem possuir alta umidade inicial, mas não se caracterizam como de comportamento recalcitrante.

As percentagens acumuladas de germinação das sementes de Eriotheca gracilipes, durante os 10 dias de experimento, indicam que, nas temperaturas constantes de 20 e $30{ }^{\circ} \mathrm{C}$ e alternada de $20-30{ }^{\circ} \mathrm{C}$, a germinação iniciou-se no quinto dia após a instalação do experimento; enquanto, a $35^{\circ} \mathrm{C}$ constante e $25-35^{\circ} \mathrm{C}$ alternado, o processo germinativo teve início no sexto dia. $\mathrm{Na}$ temperatura de $25^{\circ} \mathrm{C}$, a germinação ocorreu no quarto dia, estendendo-se até o décimo dia de observação (Figura 1).

Os resultados encontrados para a maior taxa de germinação, $70 \%$, na temperatura de $25^{\circ} \mathrm{C}$, indicam período de germinação entre quatro e nove dias, resultados diferentes dos citados por SALOMẪO et al. (1997), em que as sementes da espécie germinaram entre 6 e 12 dias, porém utilizando como substrato rolo de papel. Os mesmos autores, ao citarem o período de dias para a germinação de várias espécies da antiga família Bombacaceae, da qual Eriotheca gracilipes fazia parte, mencionam um padrão similar para a maioria, como, por exemplo, $A$. tibourbou, Ceiba pubiflora (A.St.-Hil.) K. Schum., Eriotheca pubescens (Mart. \& Zucc.) Schott \& Endel. e Guazuma ulmifolia, entre 6 e 20 dias para a germinação.

A germinação mais rápida, obtida neste experimento, pode estar relacionada ao substrato utilizado (sobre papel) ou à origem das sementes, pois de acordo com BRADFORD \& NONOGAKI (2007), na dependência da origem das sementes, estas podem ter diferentes comportamentos, fator algumas vezes ligado a subespécies adaptadas às condições locais.

Embora tenha ocorrido germinação em todos os tratamentos, as temperaturas de $30 \mathrm{e}$ $35^{\circ} \mathrm{C}$ não foram adequadas, proporcionando baixa percentagem de germinação. Também, na temperatura alternada de $25-35^{\circ} \mathrm{C}$, ocorreu menor número de sementes germinadas (Figura 2). Os melhores resultados, $67 \%\left(20^{\circ} \mathrm{C}\right), 70 \%$ $\left(25^{\circ} \mathrm{C}\right)$ e $60 \%\left(20-30^{\circ} \mathrm{C}\right)$ podem ser considerados adequados, uma vez que se trata de uma espécie florestal nativa, sem domesticação. As sementes não germinadas, após corte, apresentavam cotilédones e embriões com coloração esbranquiçada, sem sinais aparentes de deterioração.

Os resultados encontrados, com a melhor germinação, entre $20 ; 25$ e $20-30^{\circ} \mathrm{C}$, são similares aos citados por SALOMÃO et al. (1997), que recomendaram as temperaturas de 25 e $20-30^{\circ} \mathrm{C}$, com a utilização de rolo de papel; porém a percentagem de germinação encontrada por aqueles autores foi maior, atingindo $90 \%$. $\mathrm{O}$ resultado aqui obtido também indica a temperatura de $20^{\circ} \mathrm{C}$ como adequada para as sementes da espécie $E$. gracilipes. 


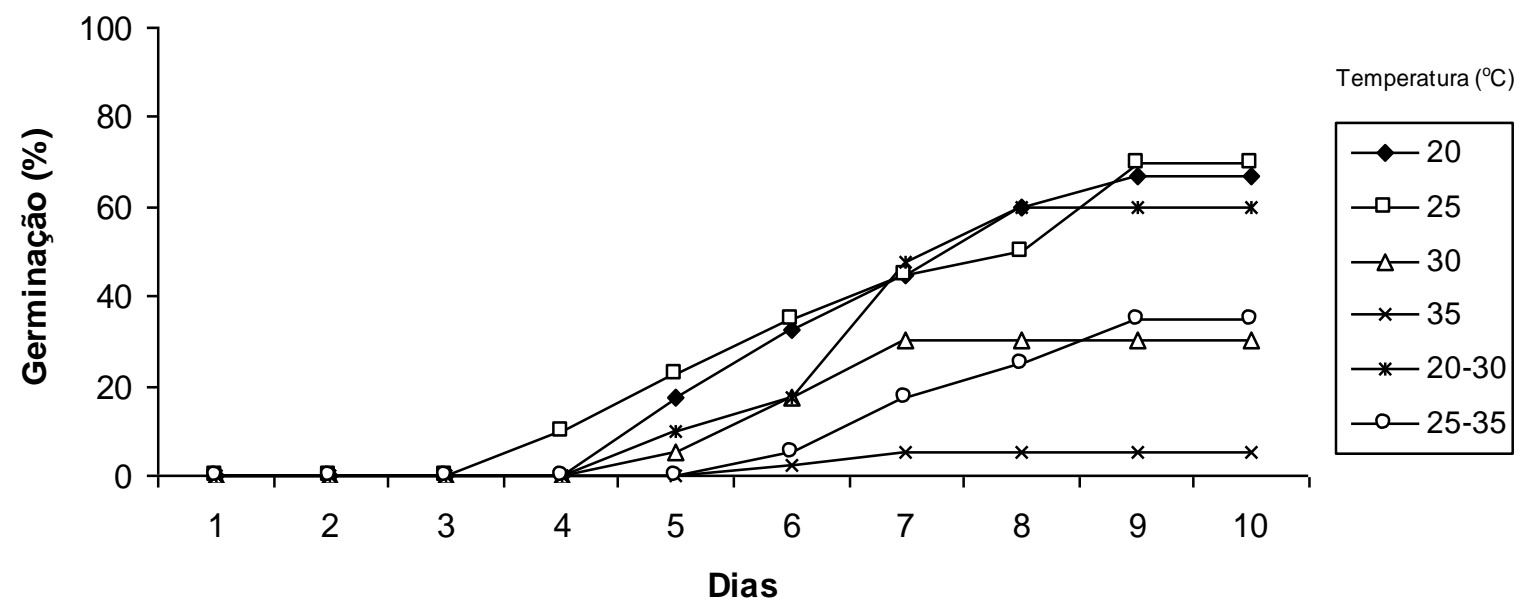

Figura 1 - Germinação acumulada (\%) de sementes de Eriotheca gracilipes em diferentes temperaturas. Accumulated germination (\%) of Eriotheca gracilipes seeds at different temperatures.

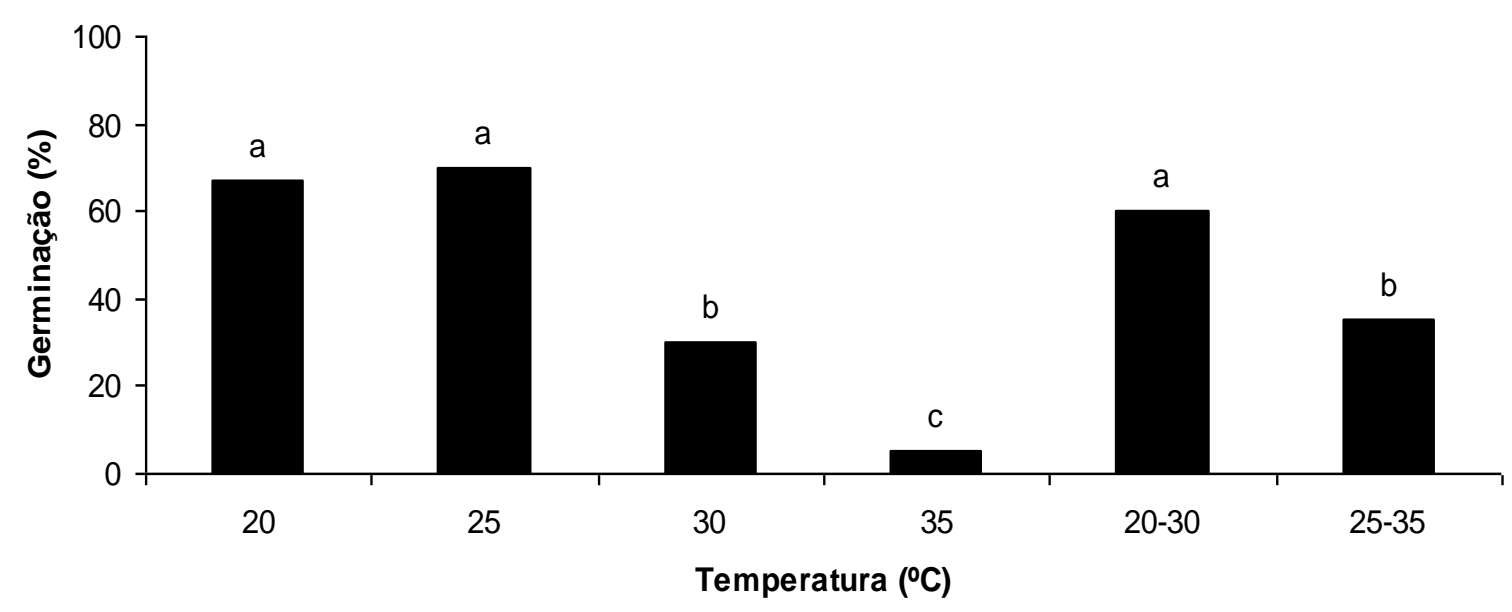

Figura 2 - Germinação (\%) de sementes de Eriotheca gracilipes em diferentes temperaturas $(\mathrm{dms}=4,75, \mathrm{CV} \%=4,88)$. As médias representadas pelas barras verticais, seguidas da mesma letra não diferem entre si, pelo teste de Tukey, a $5 \%$ de probabilidade. Eriotecha gracilipes seeds germination submitted to different temperatures (Isd $=4.75 ; \mathrm{CV} \%=4.88)$. Means represented by vertical bars, followed by the same letter are not significantly different at the level of $5 \%$ of probability, according to Tukey's test.

Trabalhando com sementes de Chorisia glaziovii (O. Kuntze) - Malvaceae, GUEDES \& ALVES (2011) também citaram a temperatura de 20-30 ${ }^{\circ} \mathrm{C}$ como adequada. Uma espécie do mesmo gênero, E. pubescens, alcançou $90 \%$ de germinação a $25^{\circ} \mathrm{C}$, em substrato papel-filtro, no escuro (SALOMÃO et al., 1997). CARRIJO et al. (2009), trabalhando também com essa mesma espécie ( $E$. pubescens), na temperatura de $25^{\circ} \mathrm{C}$, encontraram $77 \%$ de germinação, no substrato vermiculita, resultado superior ao encontrado inicialmente para a espécie em estudo, $E$. gracilipes, no primeiro teste. A menor percentagem de germinação encontrada para E. gracilipes, provavelmente, está relacionada à necessidade de utilização de diferentes substratos e temperaturas, tal como avaliado por CARRIJO et al. (2009). Outro fator que pode ter influenciado nas taxas de germinação é a origem das sementes, podendo as mesmas ter diferentes comportamentos, fato relacionado à adaptação às condições locais (BRADFORD \& NONOGAKI, 2007).

Entretanto, foi observado que sementes armazenadas por um mês, em condições de laboratório, apresentaram percentagens de germinação acima de $96 \%$, nas temperaturas de 20 e $25^{\circ} \mathrm{C}$, além de IVG de 6,3. O teste de umidade indicou $13,5 \%$ de teor de água nas sementes testadas, indicando pequena perda de água após armazenamento, com valor mais próximo ao citado para E. pubescens (11\%), com $90 \%$ de germinação (SALOMÃO et al., 1997), porém 
abaixo do relatado por CARRIJO et al. (2009), trabalhando também com $E$. pubescens, com grau médio de umidade das sementes de $5,8 \%$.

Os resultados obtidos para a germinação de E. gracilipes, após um curto período de armazenamento, indicaram maior taxa de germinação e vigor das sementes. Algumas possibilidades para esse resultado são a colheita das sementes antes do ponto de maturidade fisiológica e/ou a indução de dormência secundária nas sementes recém-colhidas pela exposição a algum fator ambiental desfavorável. Assim, durante o armazenamento, pode-se ter alcançado o ponto de maturidade fisiológica das sementes ou eliminada sua dormência secundária, propiciando maior percentagem de germinação e vigor das sementes armazenadas em relação às recém-colhidas. As informações disponíveis sobre a espécie não indicam qualquer tipo de dormência nas sementes. De acordo com SALOMÃO et al. (1997), para a germinação de sementes de $E$. gracilipes, não é necessário nenhum tratamento, embora esses autores não informem se a espécie possui ou não dormência; por outro lado, informam que outra espécie do mesmo gênero, E. pubescens, não apresenta dormência.

Em relação ao índice de velocidade de germinação (IVG), os maiores valores foram obtidos para as temperaturas de $20 ; 25$ e $20-30^{\circ} \mathrm{C}$, com as sementes germinando em maior número no menor período de tempo, indicando serem estas as temperaturas mais adequadas para a espécie. Em relação ao tempo médio de germinação (TMG), com exceção da temperatura de $30^{\circ} \mathrm{C}$, com alto TMG, as demais temperaturas foram estatisticamente iguais, com as sementes germinando em curto espaço de tempo, o que é benéfico, pois as que demoram muito para germinar podem ser atacadas por fungos durante 0 processo de embebição e não germinar. Portanto, lotes que apresentem maior velocidade durante o processo de germinação, ou seja, alto vigor, deverão sofrer menor influência de patógenos (BRADFORD \& NONOGAKI, 2007).

Os resultados encontrados demonstram que, em relação à outra espécie do mesmo gênero, E. pubescens, com IVG variando de 4,8 a 8,8 (CARRIJO et al., 2009), E. gracilipes demanda mais tempo para germinar, com menor número de sementes germinando. Porém, avaliando-se as sementes germinadas após armazenamento, o IVG atinge valor de 6,3, similar aos encontrados para $E$. pubescens.

A temperatura foi um fator importante na germinação de sementes de Eriotheca gracilipes, influenciando no total de germinação e no vigor das sementes, medidos através da velocidade de germinação e do tempo médio de germinação. Segundo BORGHETTI \& FERREIRA (2004), a redução do tempo médio de germinação na tem- peratura ótima pode estar relacionada com a rápida colonização do ambiente. Levando-se em consideração que esta espécie não é considerada pioneira, temperaturas mais amenas podem facilitar o processo de germinação em áreas de dossel fechado, onde a temperatura é mais constante.

De acordo com LARCHER (2003) e BRADFORD \& NONOGAKI (2007), geralmente quando as sementes são submetidas a diferentes temperaturas, podem-se observar os seguintes aspectos: i) as sementes podem não germinar em temperaturas menores, caracterizando estas como temperatura mínima, abaixo da qual o processo não ocorre; ii) podem ter o processo germinativo acelerado, aumentando de acordo com o aumento da temperatura, caracterizando a faixa infra-ótima; iii) a velocidade do processo germinativo pode diminuir com o aumento da temperatura, indicando a faixa supra-ótima, e iv) as sementes podem não germinar em temperatura muito alta, com a ocorrência da temperatura máxima, acima da qual o processo não ocorre. A temperatura ótima seria aquela em que o processo ocorre em maior intensidade e velocidade, no menor espaço de tempo, o que foi observado para as temperaturas de 20; 25 e 20-30 ${ }^{\circ} \mathrm{C}$.

Algumas espécies podem germinar em um amplo espectro de temperatura, como citado por MATHEUS \& LOPES (2009), trabalhando com sementes de Erythrina variegata L., em que as sementes germinaram entre 14 e $38^{\circ} \mathrm{C}$, mas com germinação ótima entre 32 e $34^{\circ} \mathrm{C}$. Isso indica que algumas espécies podem germinar em um amplo espectro de temperatura, mas o melhor desempenho está situado em uma faixa estreita, em que a percentagem e o vigor das sementes são maiores. Em relação às temperaturas testadas, a germinação das sementes de Eriotheca gracilipes aconteceu em todas as temperaturas, fator provavelmente relacionado às suas características ecológicas, embora as temperaturas mais elevadas, 30 ; 35 e $25-35^{\circ} \mathrm{C}$ tenham resultado em menor taxa de germinação e índice de velocidade de germinação (Figura 2 e Tabela 1).

O resultado encontrado para a temperatura de $20^{\circ} \mathrm{C}$ não é muito comum em trabalhos com espécies tropicais. Segundo CASSAROSILVA (2001), existe grande dependência entre a velocidade de germinação e a temperatura; assim, quanto menor a temperatura, maior seria o tempo necessário para que as sementes germinem e menor a percentagem total de germinação; porém para Eriotheca gracilipes, as temperaturas mais baixas não influenciaram negativamente no processo de germinação ou na formação de plântulas. 
Tabela 1 - Índice de velocidade de germinação (IVG) e tempo médio de germinação (TMG) de sementes de Eriotheca gracilipes submetidas a diferentes temperaturas. Speed of germination index (IVG) and mean time for germination (TMG) of Eriotecha gracilipes seeds submitted to different temperatures.

\begin{tabular}{ccc}
\hline Temperatura $\left({ }^{\circ} \mathrm{C}\right)$ & ${ }^{(1)}$ IVG & (1) TMG (dias) \\
\hline 20 & $2,6 \mathrm{a}$ & $1,7 \mathrm{a}$ \\
25 & $2,8 \mathrm{a}$ & $1,7 \mathrm{a}$ \\
30 & $1,2 \mathrm{~b}$ & $6,2 \mathrm{~b}$ \\
35 & $0,2 \mathrm{c}$ & $1,6 \mathrm{a}$ \\
$20-30$ & $2,3 \mathrm{a}$ & $1,7 \mathrm{a}$ \\
$25-35$ & $1,2 \mathrm{~b}$ & $1,9 \mathrm{a}$ \\
\hline & ${ }^{(2)} \mathrm{dms}=0,35$ & ${ }^{(2)} \mathrm{dms}=0,32$ \\
& ${ }^{(3)} \mathrm{CV} \%=9,31$ & ${ }^{(3)} \mathrm{CV} \%=5,89$ \\
\hline
\end{tabular}

(1) As médias seguidas da mesma letra não diferem entre si, pelo teste de Tukey, a $5 \%$ de probabilidade;

(2) Diferença mínima significativa; ${ }^{(3)}$ Coeficiente de variação.

Alguns trabalhos apontam que a temperatura ótima para germinação de sementes está entre 25 e $30^{\circ} \mathrm{C}$, a exemplo do reportado por GUEDES \& ALVES (2011) para sementes de Chorisia glaziovii (O. Kuntze), em que as temperaturas de $25^{\circ} \mathrm{C}$ e $20-30{ }^{\circ} \mathrm{C}$ foram as mais adequadas e, também, por LADEIA et al. (2011), em que a temperatura de $30^{\circ} \mathrm{C}$ promoveu a máxima germinação de sementes de Pseudobombax longiflorum (Mart. et Zucc.) A. Robyns.

De acordo com CASTRO et al. (2004), a energia cinética aumenta em resposta à elevação da temperatura, propiciando aumento da pressão de difusão e maior absorção de água, o que pode acelerar o processo germinativo. Este efeito sobre a embebição foi observado até a temperatura constante de $25^{\circ} \mathrm{C}$ (Figura 2); porém a 30 e $35{ }^{\circ} \mathrm{C}$ e $25-35{ }^{\circ} \mathrm{C}$ ocorreu menor germinabilidade. MARCOS FILHO (2005) e BRADFORD \& NONOGAKI (2007) afirmam que, em temperaturas mais elevadas, pode ocorrer danos às estruturas das sementes, afetando negativamente a germinação, através do impedimento do desenvolvimento do embrião devido a possíveis alterações enzimáticas, por exemplo.

CASSARO-SILVA (2001) relata que, em temperaturas supraótimas ou muito elevadas, em relação àquelas que a espécie tolera, a energia contida nas células ou sistemas de membranas celulares da semente fica cada vez menos favorável ao crescimento do embrião, até atingir a temperatura máxima em que toda a energia é dissipada; neste ponto, ocorrem processos como a desnaturação de proteínas, limitando a germinação.

Contudo, temperaturas ambientais baixas podem resultar em menor estabelecimento de plântulas e em redução da biomassa, principalmente entre espécies tropicais e subtropicais, sendo que a extensão do dano depende da espécie, do conteúdo inicial de água da semente, da temperatura e da duração da exposição a este fator (LARCHER, 2003; BRADFORD \& NONOGAKI, 2007), o que não foi observado para esta espécie, na temperatura de $20^{\circ} \mathrm{C}$.

De acordo com SANGALLI et al. (2012), temperaturas inferiores ou superiores à ótima tendem a reduzir a velocidade do processo germinativo, expondo as plântulas por maior período a fatores adversos. CARVALHO \& NAKAGAWA (2012) também mencionam que temperaturas inferiores à ótima possuem 0 mesmo efeito, tendendo a reduzir a velocidade do processo de germinação e o crescimento. Dentre as temperaturas testadas, $35^{\circ} \mathrm{C}$ foi a que interferiu mais negativamente no processo de crescimento, não permitindo o desenvolvimento.

Em relação ao comprimento médio das raízes primárias, as temperaturas de 20; 25 e 20-30 ${ }^{\circ} \mathrm{C}$ não diferiram estatisticamente entre si; porém foram estatisticamente superiores às demais temperaturas (Tabela 2). Essas temperaturas também promoveram maior massa média de matéria seca, não diferindo entre si, porém superando os demais tratamentos. Esses resultados indicam que as temperaturas mais adequadas para germinação $\left(20 ; 25\right.$ e $\left.20-30{ }^{\circ} \mathrm{C}\right)$ também foram as propicias para o crescimento inicial da raiz primária, gerando o mesmo padrão, tanto em comprimento como em massa (Tabela 2).

De acordo com LARCHER (2003), para espécies lenhosas de regiões tropicais, temperaturas acima de $10^{\circ} \mathrm{C}$ são necessárias para o crescimento em extensão da raiz primária, com temperatura ótima para a divisão celular de aproximadamente $30^{\circ} \mathrm{C}$ para a maioria das espécies, portanto próxima da temperatura ótima para o crescimento. Para Eriotheca gracilipes, também as melhores temperaturas para crescimento foram encontradas abaixo de $30^{\circ} \mathrm{C}$ (Tabela 2).

Em relação ao crescimento inicial das estruturas em temperaturas alternadas (e também a germinação), BRADFORD \& NONOGAKI (2007) colocam que estes fatores podem estar associados à presença de mecanismos enzimáticos específicos, que funcionam em diferentes temperaturas, resultado de adaptações ecológicas da espécie ao ambiente. Por exemplo, para 
sementes de algumas espécies tropicais, temperaturas constantes e também a alternância de temperatura podem proporcionar melhores condições de germinação e crescimento da plântula. Trabalho desenvolvido por OLIVEIRA \& PEREIRA (2014), com sementes de uma espécie da família Fabaceae, Guibourtia hymenaefolia
(Moric.) J. Léonard), indicaram que temperaturas alternadas de $20-30$ e $25-35^{\circ} \mathrm{C}$ foram eficientes para promover a germinação e o crescimento inicial das plântulas, resultado similar ao encontrado para a espécie em estudo, Eriotheca gracilipes, em relação ao seu comportamento em temperaturas alternadas.

Tabela 2 - Massa seca $(\mathrm{g})$ e comprimento médio $(\mathrm{mm})$ de raízes primárias de Eriotheca gracilipes em diferentes temperaturas. Dry mass $(\mathrm{g})$ and mean length $(\mathrm{mm})$ of primary roots of Eriotecha gracilipes seedlings in a germination test conducted under different temperatures.

\begin{tabular}{ccc}
\hline Temperatura $\left({ }^{\circ} \mathrm{C}\right)$ & ${ }^{(1)}$ Massa seca $(\mathrm{g})$ & (1) \\
\hline 20 & $0,46 \mathrm{a}$ & $3,9 \mathrm{a}$ \\
25 & $0,48 \mathrm{a}$ & $3,3 \mathrm{a}$ \\
30 & $0,24 \mathrm{~b}$ & $2,0 \mathrm{~b}$ \\
35 & $0,0 \mathrm{c}$ & $0,0 \mathrm{c}$ \\
$20-30$ & $0,41 \mathrm{a}$ & $3,5 \mathrm{a}$ \\
$25-35$ & $0,21 \mathrm{~b}$ & $2,2 \mathrm{~b}$ \\
\hline & ${ }^{(2)} \mathrm{dms}=0,06$ & ${ }^{(2)} \mathrm{dms}=0,62$ \\
& ${ }^{(3)} \mathrm{CV} \%=11,83$ & $(3) \mathrm{CV} \%=12,75$
\end{tabular}

(1) Médias seguidas da mesma letra não diferem estatisticamente entre si, pelo teste de Tukey $(p<0,05)$;

(2) Diferença mínima significativa; ${ }^{(3)}$ Coeficiente de variação.

Para as sementes de Eriotheca gracilipes, no entanto, as temperaturas alternadas favoreceram o processo germinativo apenas na temperatura de $20-30^{\circ} \mathrm{C}$, afetando negativamente em $25-35^{\circ} \mathrm{C}$, novamente demonstrando que temperaturas mais elevadas diminuem o processo germinativo e também o crescimento da raiz. Podese supor que, em temperaturas altas, como $35{ }^{\circ} \mathrm{C}$, a atividade respiratória tenha-se sobressaído em relação aos demais processos fisiológicos e que as sementes tenham esgotado suas reservas antes de germinar ou tenha ocorrido um processo de desnaturação de determinadas enzimas e proteínas mais sensíveis a temperaturas elevadas (CASSARO-SILVA, 2001), pois cada proteína suporta certa temperatura máxima (CAVALCANTI et al., 2010); assim, tanto o esgotamento das reservas como a desnaturação podem ter levado as sementes à morte ou resultado em plântulas de menor massa.

Em trabalho com Araucaria angustifolia (Bertoloni) Otto Kuntze, AMARANTE et al. (2007) investigaram a taxa respiratória das sementes a diferentes temperaturas e verificaram um aumento dessa taxa progressivamente até $40^{\circ} \mathrm{C}$, o que pode resultar em desnaturação de estruturas. No entanto, a maioria dos trabalhos não leva em consideração a perda de material estrutural durante esta situação, talvez devido às dificuldades metodológicas para esse tipo de estudo.

\section{Conclusões}

As sementes de Eriotheca gracilipes possuem maior taxa de germinação e de crescimento da raiz em temperaturas constantes de 20 e $25^{\circ} \mathrm{C}$ e alternada de $20-30{ }^{\circ} \mathrm{C}$.

\section{Agradecimentos}

Os autores agradecem à Universidade Anhanguera-Uniderp pelo financiamento do projeto GIP (Grupo Interdisciplinar de Pesquisa) e pela bolsa concedida (PIC), e ao Conselho Nacional de Desenvolvimento Científico e Tecnológico (CNPq), pelas bolsas de Iniciação Científica (PIBIC) e de Produtividade em Pesquisas concedidas. Também agradecem aos pareceiristas pelas sugestões e críticas.

\section{Referências}

AMARANTE, C. V. T.; MOTA, C. S.; MEGGUER, C. A.; IDE, G. M. Conservação pós-colheita de pinhões [sementes de Araucaria angustifolia (Bertoloni) Otto Kuntze] armazenados em diferentes temperaturas. Ciência Rural, Santa Maria, v.37, n.2, p.346-351, 2007.

BORGHETTI, F.; FERREIRA, A. G. Interpretação de resultados de germinação. In: FERREIRA, A. G.; BORGHETTI, F. Germinação: do básico ao aplicado. Porto Alegre: Artmed, 2004. p.209-222.

BRADFORD, K. J.; NONOGAKI, H. Seed development, dormancy and germination. Oxford: Blackwell Publishing, 2007. 392p.

BRANCALION, P. H. S.; NOVEMBRE, A. D. L. C.; RODRIGUES, R. R. Temperatura ótima de germinação de sementes de espécies arbóreas brasileiras. Revista Brasileira de Sementes, Viçosa, MG, v.32, n.4, p.15-21, 2010. 
BRASIL. Ministério da Agricultura, Pecuária e Abastecimento. Regras para análise de sementes. Brasília: Secretaria de Defesa Agropecuária, 2009. 395p.

CARVALHO, P. E. R. Espécies arbóreas brasileiras. Brasília: Embrapa Informação Tecnológica; Colombo: Embrapa Florestas, 2003. v.1, 1039p.

CARVALHO, P. E. R. Espécies arbóreas brasileiras. Brasília: Embrapa Informação Tecnológica; Colombo: Embrapa Florestas, 2006. v.2, 627p.

CARVALHO, P. E. R. Espécies arbóreas brasileiras. Brasília: Embrapa Informação Tecnológica; Colombo: Embrapa Florestas, 2008. v.3, $593 p$.

CARVALHO, P. E. R. Espécies arbóreas brasileiras. Brasília: Embrapa Informação Tecnológica; Colombo: Embrapa Florestas, 2010. v.4, 644p.

CARVALHO, N. M.; NAKAGAWA, J. Sementes: ciência, tecnologia e produção. 5.ed. Jaboticabal: FUNEP, 2012. 590p.

CARRIJO, C.; MARTINS R. C. C.; MARTINS, I. S.; LANDAHL, D. T.; MATOS, J. M. M.; NAKANO, T. Y. R. Estabelecimento de Eriotheca pubescens (Bombacaceae) por meio de semeadura direta e de mudas em cascalheira. Cerne, Lavras, v.15, n.3, p.365-370, 2009.

CASSARO-SILVA, M. Efeito da temperatura na germinação de sementes de manduirana (Senna macranthera (Collad.) Irwin et Barn. - Caesalpiniaceae). Revista Brasileira de Sementes, Viçosa, MG, v.23, n.1, p.92-99, 2001.

CASTRO, R. D.; BRADFORD, K. J.; HILHORST, H. W .M. Embebição e reativação do metabolismo. In: FERREIRA, A. G.; BORGHETTI, F. Germinação: do básico ao aplicado. Porto Alegre: Artmed, 2004. p.149-162.

CAVALCANTI, M. T.; BORA, P. S.; FLORÊNCIO, I. M.; FLORENTINO, E. R.; SILVA, F. L. H. Avaliação da estabilidade térmica das proteínas das amêndoas da faveleira (Cnidosculus phyllacanthus (Mart) Pax. Et K. Hoffm). Revista Brasileira de Produtos Agroindustriais, Campina Grande, v.12, n.1, p.37-43, 2010.

FRANCISCO, M. R.; LUNARDI, V. O.; GUIMARÃES JR., P. R.; GALETTI, M. Factors affecting seed predation of Eriotheca gracilipes (Bombacaceae) by parakeets in a cerrado fragment. Acta Oecologica, Montrouge, v.33, n.2, p.240-245, 2008.
GUARIM NETO, G.; MORAIS, R. G. Recursos medicinais de espécies do Cerrado de Mato Grosso: um estudo bibliográfico. Acta Botanica Brasilica, São Paulo, v.17, n.4, p.561-584, 2003.

GUEDES, R. S.; ALVES, E. U. Substratos e temperaturas para 0 teste de germinação de sementes de Chorisia glaziovii (O. Kuntze). Cerne, Lavras, v.17, n.4, p.525-531, 2011.

LABOURIAU, L. G. Germinação das sementes. Washington: Organização dos Estados Americanos, 1983. 174p.

LABOURIAU, L. G.; AGUDO, M. On the physiology of seed germination in Salvia hispanica L. I Temperature effects. Anais da Academia Brasileira de Ciências, Rio de Janeiro, v.59, n.1, p.37-50, 1987.

LADEIA, E. S.; COELHO, M. F. B.; AZEVEDO, R. A. B. Germinação de sementes de Pseudobombax longiflorum (Mart. et Zucc.) A. Robyns. (Malvaceae) de duas procedências em diferentes temperaturas. Revista de Ciências Agrárias, Belém, v.54, n.3, p.290-298, 2011.

LARCHER, W. Physiological plant ecology: ecophysiology and stress physiology of functional groups. Berlin: Springer, 2003. 533p.

LORENZI, H. Árvores brasileiras: manual de identificação e cultivo de plantas arbóreas nativas do Brasil. 5.ed. Nova Odessa: Instituto Plantarum, 2008. v.1, 384p.

MAGUIRE, J. D. Speed of germination aid in selection and evaluation for seedling and vigour. Crop Science, Madison, v.2, n.176-177, 1962.

MARCOS FILHO, J. Fisiologia de sementes de plantas cultivadas. Piracicaba: FEALQ, 2005. 495p.

MATHEUS, M. T.; LOPES, J. C. Temperaturas cardinais para a germinação de sementes de Erythrina variegata L. Revista Brasileira de Sementes, Viçosa, MG, v.31, n.3, p.115-122, 2009.

OLIVEIRA, A. K. M.; PEREIRA, K. C. L.. Efeito de diferentes temperaturas na germinação e crescimento radicular de sementes de jatobámirim (Guibourtia hymenaefolia (Moric.) J. Léonard). Ciência Florestal, Santa Maria, v.24, n.1, p.111-116, 2014.

RIBEIRO, J. F.; WALTER, B. M. T. Fitofisonomias do bioma Cerrado. In: SANO, S. M.; ALMEIDA, A. P. Cerrado: ambiente e flora. Planaltina: Embrapa-CPAC, 1998. p.89-166. 
SALOMÃO, A. N.; EIRA, M. T. S.; CUNHA, R.; SANTOS, I. R. I.; MUNDIM, R. C.; REIS, R. B. Padrões de germinação e comportamento para fins de conservação de sementes de espécies autóctones: madeireiras, alimentícias, medicinais e ornamentais. Brasília: Embrapa, Centro Nacional de Pesquisa de Recursos Genéticos e Biotecnologia, 1997. p.1-12. (Comunicado Técnico, 23).

SALOMÃO, A. N.; SOUSA-SILVA, J. C.; DAVIDE, A. C.; GONZÁLES, S.; TORRES, R. A. A.; WETZEL, M. M. V. S.; FIRETTI, F.; CALDAS, L. S. Germinação de sementes e produção de mudas de plantas do Cerrado. Brasília: Rede de Sementes do Cerrado, 2003. 96p.
SANGALLI, A.; VIEIRA, M. C.; SCALON, S. P. Q.; ZÁRATE, N. A. H.; SILVA, C. B.; RIBEIRO, I. S. Morfometria de frutos e sementes e germinação de carobinha (Jacaranda decurrens subsp. symmetrifoliolata Farias \& Proença), após o armazenamento. Revista Brasileira de Plantas Medicinais, Botucatu, v.14, n.2, p.267-275, 2012. 